\title{
Process for the Obtention of Coumaric Acid from Coumarin: Analysis of the Reaction Conditions
}

\author{
Néstor N. López-Castillo ${ }^{1}$, Alma D. Rojas-Rodríguez ${ }^{2}$, Brenda M. Porta ${ }^{1}$, M. Javier Cruz-Gómez ${ }^{1}$ \\ ${ }^{1}$ Chemical Engineering Department of the Faculty of Chemistry, Universidad Nacional Autónoma de México (UNAM) Coyoacan, \\ D. F. México, México \\ ${ }^{2}$ Faculty of Engineering, Universidad Anáhuac México Norte, D. F. México, México \\ Email: mjcg@unam.mx
}

Received March 13, 2013; revised April 13, 2013; accepted May 10, 2013

Copyright (C 2013 Néstor N. López-Castillo et al. This is an open access article distributed under the Creative Commons Attribution License, which permits unrestricted use, distribution, and reproduction in any medium, provided the original work is properly cited.

\begin{abstract}
Coumaric acid can be obtained from basic hydrolysis of coumarin, through a reaction process consisting on opening the lactone ring and cis-trans isomerization. Parameters such as reaction time, temperature, $\mathrm{NaOH}$ concentration, solvent and reaction atmosphere, have been thoroughly studied and analyzed, in order to determine the appropriate conditions for the maximum conversion efficiency of coumarin into coumaric acid. Experimental results show that the best conditions are a 1 hour reaction time, at $160^{\circ} \mathrm{C}$, with a $20 \%$ sodium hydroxide aqueous solution, and in an inert reaction atmosphere.
\end{abstract}

Keywords: Coumarin; Coumaric Acid; Ester Hydrolysis

\section{Introduction}

Coumarin, a source for coumaric acid, was identified in 1820 and 1868, was synthesized in a laboratory for the first [1]. It is a pleasant smelling compound which gives a characteristic odor to hay. Other simple coumarins also possess characteristic smells sometimes exploited in perfumery [2].

Coumarin derivatives also have diverse biological properties, such as enzyme inhibition, hypotoxicity, as well as, carcinogenic, anticoagulant or antibiotic action [3]. Also, some are used as dyes given their efficient light emission properties, high stability, and ease of synthesis [4].

The bicyclic ring system of chromenes, like coumarin, has inspired a number of different synthetic approaches $[5,6]$.

The purpose of this research was to determine the best process conditions (time, temperature, $\mathrm{NaOH}$ concentration and solvent, and reaction atmosphere) to obtain coumaric acid from basic hydrolysis of coumarin.

Several processes have already been developed for the conversion of coumarin into coumaric acid. Scheme 1 shows one of these methods; where coumarin (1) converts into o-coumaric acid (2) via reflux with sodium ethoxide during four hours; then, the mixture is diluted with water, removing most of the solvent with vacuum, and neutralizing the residue with concentrated hydrochloric acid $[7,8]$.

Other method (Scheme 2) establishes that strong nucleophiles, such as hydroxide ions, open the coumarin ring as a result of an attack at C-2 [1,9]. Initially, the double bond is cis, this product is known as coumarinic acid (3). Acidification of the solution at this stage is followed by rapid cyclization to reform coumarin (even under slightly basic conditions). However, on prolonged contact with the base, the cis-acid slowly isomerizes into trans-isomer (4) (known as coumaric acid). Acidification at this step allows isolating free hydroxy-acid.<smiles>O=c1ccc2ccccc2o1</smiles>

(1)

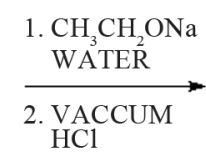<smiles>O=C(O)/C=C/c1ccccc1O</smiles>

(2)
Scheme 1. Reaction to obtain coumaric acid from coumarin.<smiles>O=c1ccc2ccccc2o1</smiles>

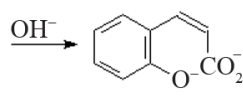

(3)

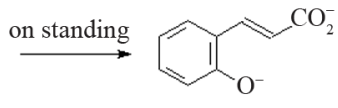

(4)
Scheme 2. Reaction to obtain coumaric acid from coumarin with strong nucleophiles. 
Other authors point out that when coumarin is treated with ethanolic sodium ethoxide at reflux, the lactone ring is opened (Scheme 3) to give 2-(ethylpropenoate)-phenoxide (5). Subsequent treatment of (5) with water and evaporation of the solvent brought about saponification of the ester and, with careful acidification, produces ocoumaric acid [10-12].

Other technique [13-15] establishes that when coumarin is heated with a sodium bisulfite solution, it dissolves completely and a sulfonate compound (6) is formed (Scheme 4), which contains the lactone ring intact. Alkali splits off the sulfo group, liberating coumarin, which recombines with neutral sulfite and forms a hydrocoumaric acid derivative. The hydrocoumaric sodium sulfonate (7) is treated with $50 \%$ potassium hydroxide solution and the mixture is evaporated to dryness in a water bath. The residue is then dissolved in water, and the cooled solution is acidified with hydrochloric acid. The precipitate obtained is coumaric acid.

\section{Materials and Methods}

\subsection{Reaction}

Coumarin $(0.137 \mathrm{~mol})$ was dissolved in a sodium hydroxide solution on a PARR reactor. The reactor was purged for about 15 to 20 minutes, to maintain the required reaction atmosphere.

When the reaction was finished, the reaction mixture was cooled into a flask, which was set into an ice bath to reach $4^{\circ} \mathrm{C}$. Afterwards, concentrated hydrochloric acid was slowly added, until a white precipitate appeared at pH 5.

The precipitate, mostly coumaric acid, was filtrated and washed with cold water. Then, more hydrochloric acid was added to the liquid phase until a second precipitate appeared. Used reagents like $\mathrm{H}_{2} \mathrm{O}, \mathrm{HCl}$, and $\mathrm{NaOH}$ were of AR grade.

\subsection{Purification}

The precipitate, containing coumaric acid and coumarin, was placed in a solid-liquid extraction system (Soxhlet) with chloroform. Coumarin was extracted and coumaric acid remained in the extraction thimble.

\subsection{Analysis methods}

The chemical composition of the products was determined by Gas chromatography. The sample was heated from $50^{\circ} \mathrm{C}$ up to $100^{\circ} \mathrm{C}$ at $20^{\circ} \mathrm{C} / \mathrm{min}$, then kept at $100^{\circ} \mathrm{C}$ for 3 minutes and heated again to $300^{\circ} \mathrm{C}$ at the same heating rate. Afterwards, the sample was kept at $300^{\circ} \mathrm{C}$, for 3.5 minutes. The equipment was flushed with helium at $2.0 \mathrm{~mL} / \mathrm{min}$ and at pressure of 15.5 psi.

\section{Results and Discussion}

\subsection{Effect of Reaction Atmosphere}

The effect of reaction atmosphere was studied for coumarin reaction with $20 \%$ of $\mathrm{NaOH}$ on water at constant temperature of $160^{\circ} \mathrm{C}$ and $1 \mathrm{~h}$ time period.

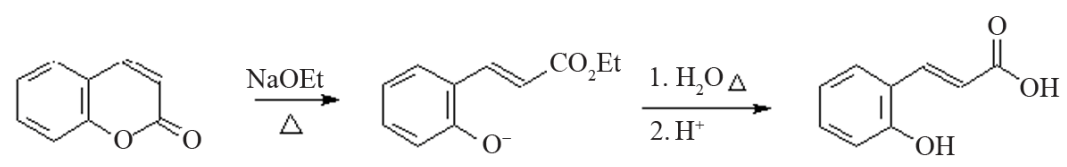

(5)

Scheme 3. Reaction to obtain coumaric acid from coumarin using ethanolic sodium ethoxide.

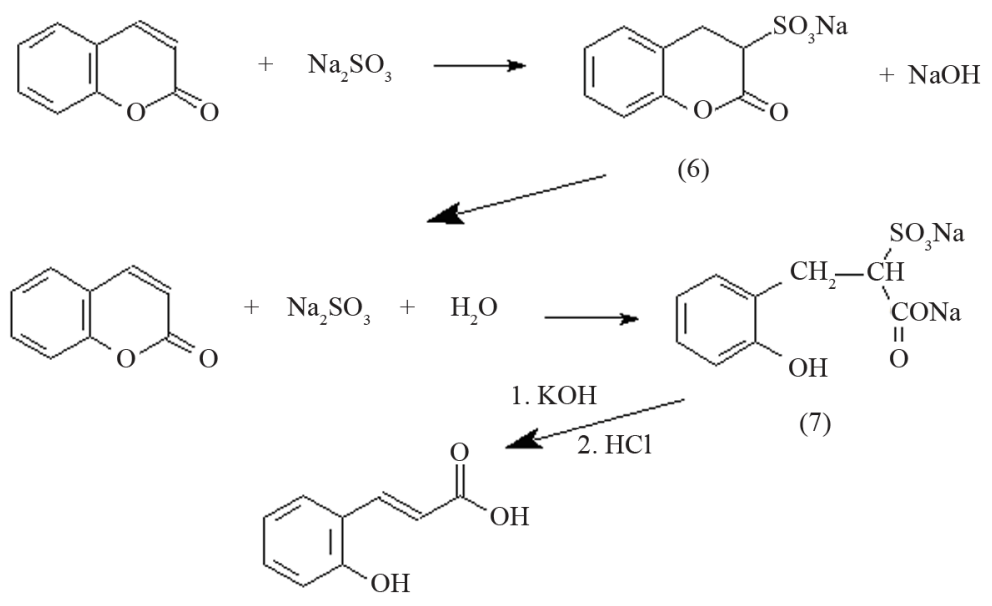

Scheme 4. Reaction to obtain coumaric acid from coumarin using sodium bisulfite. 
Figure 1 shows the necessity of using an inert atmosphere. When the reaction is carried out without eliminating air from the medium, the mixture favors oxidation reactions to give by-products, which complicate the handling of material and the yield decreases (Table 1). Therefore, it was decided to pass an inert gas for 20 minutes to eliminate the air from the medium.

\subsection{Effect of the Reaction Temperature}

The effect of the reaction temperature on the conversion of coumarin into coumaric acid is displayed in Figure 2, for $1 \mathrm{~h}$ time period, $20 \% \mathrm{NaOH}$ aqueous solution, and in a helium atmosphere. The amount of reaction yield is shown in Table 2.

Table 1. Effect of the reaction atmosphere.

\begin{tabular}{cccc}
\hline $\begin{array}{c}\text { Reaction } \\
\text { atmosphere }\end{array}$ & Helium & Nitrogen & Air \\
\hline Yield [\%] & 71.7 & 59.0 & 22.8 \\
\hline
\end{tabular}

Table 2. Effect of the reaction temperature.

\begin{tabular}{ccccc}
\hline $\begin{array}{c}\text { Reaction temperature } \\
{\left[{ }^{\circ} \mathrm{C}\right]}\end{array}$ & 140 & 160 & 180 & 200 \\
\hline Yield [\%] & 21.3 & 71.7 & 53.1 & 55.0 \\
\hline
\end{tabular}

Below $120^{\circ} \mathrm{C}$, there is not conversion of coumarin into coumaric acid, and above $180^{\circ} \mathrm{C}$ by-products are obtained (Figure 3). The peaks found at $5.77 \mathrm{~min}$ and 6.21 min correspond to phenol and 2-hydroxybenzaldehyde, respectively. These two compounds are due to the oxidation of the product, and the presence of them can be observed when the final reaction mixture has an orange color instead of a yellow one. When they are contained in the final reaction mixture, acidification gives a new tacky material, which complicates the handling of the product, as well as the purification process. The temperature at which the best yield is obtained is $160^{\circ} \mathrm{C}$.

\subsection{Effect of the Sodium Hydroxide Concentration}

The effect of $\mathrm{NaOH}$ concentration on coumaric acid production was studied using different concentrations within the range of $10 \%-25 \%$, at a constant temperature of $160^{\circ} \mathrm{C}$, and in a helium atmosphere. Results, shown in Figure 4 and Table 3, reveal that the best yield of coumaric acid was obtained at 20 wt.\% of $\mathrm{NaOH}$ in the reaction mixture. An increase in the caustic soda content produces a variation in the yield, since by-products such as phenol may appear and complicate the purification process. Thus, 20 wt.\% sodium hydroxide solution addition is considered to be the optimum concentration.

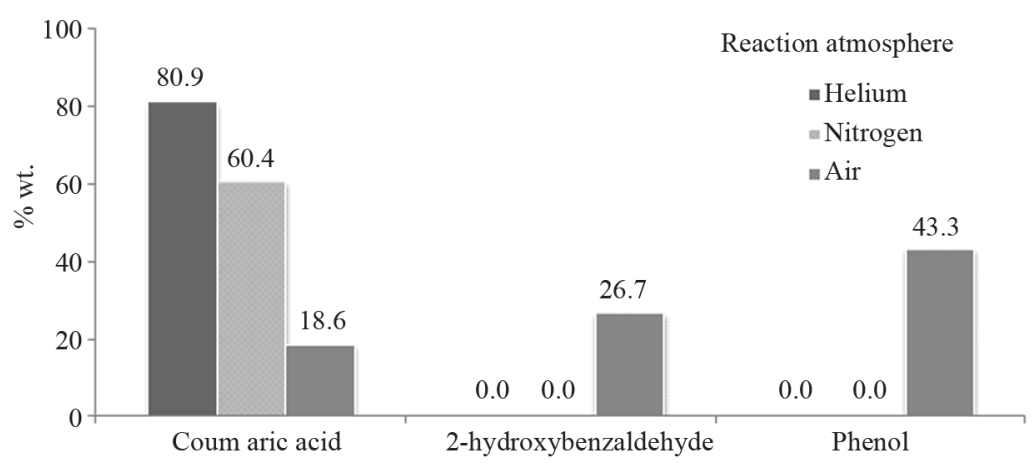

Figure 1. Effect of the reaction atmosphere.

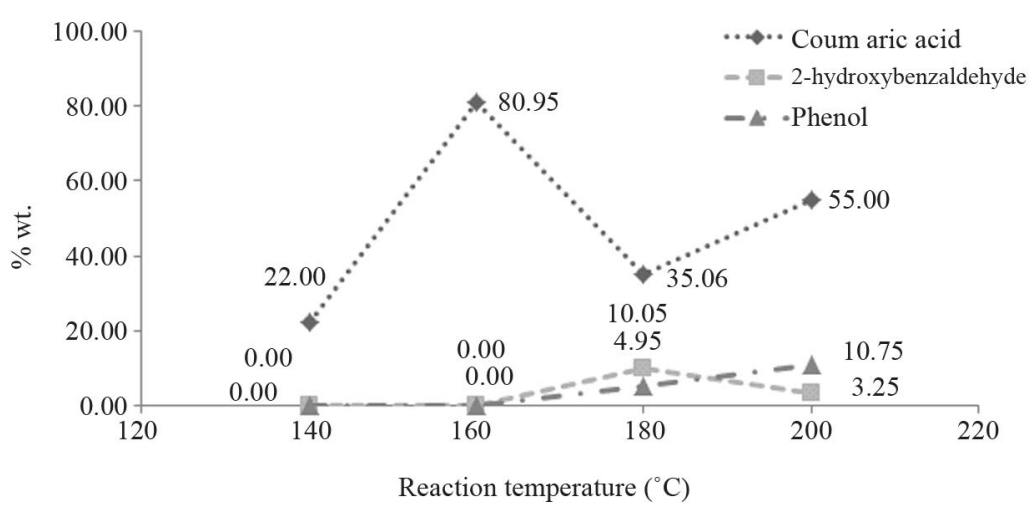

Figure 2. Effect of the reaction temperature. 


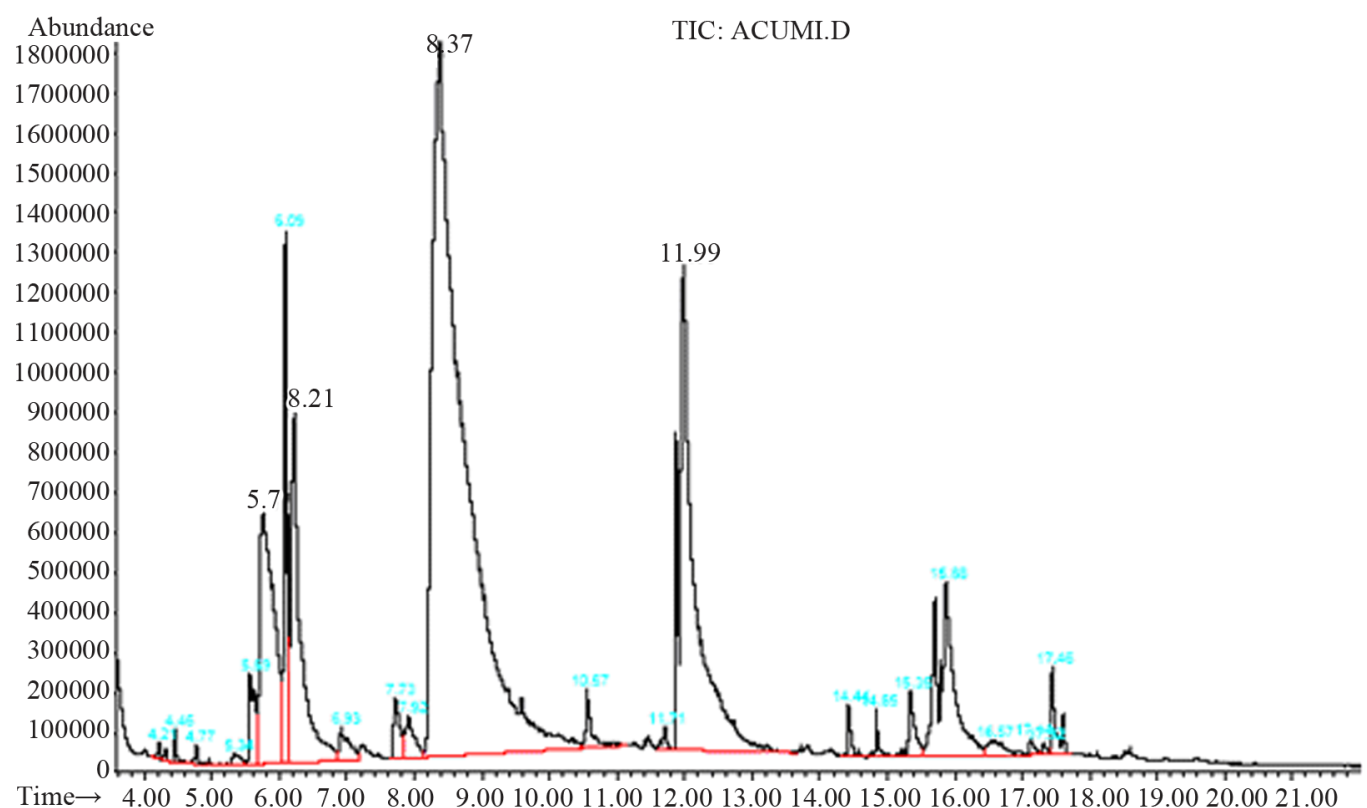

Figure 3. Chromatogram of by-products obtained when the reaction was carried out at temperatures above $180^{\circ} \mathrm{C}$.

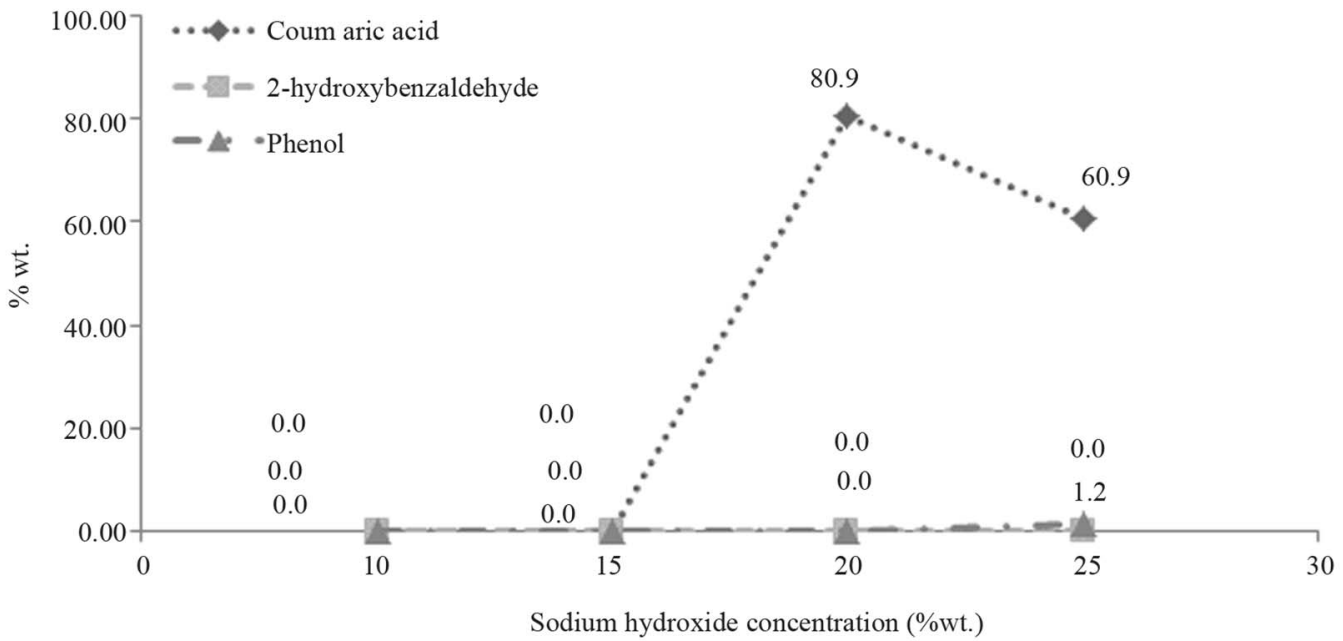

Figure 4. Effect of the sodium hydroxide concentration.

Table 3. Effect of the sodium hydroxide concentration.

\begin{tabular}{ccccc}
\hline $\begin{array}{c}\text { Sodium hydroxide } \\
\text { concentration [\%wt.] }\end{array}$ & 10 & 15 & 20 & 25 \\
\hline Yield [\%] & 0.0 & 0.0 & 71.7 & 55.0 \\
\hline
\end{tabular}

\subsection{Effect of the Reaction Time}

The reaction of coumarin was carried out with $20 \%$ of $\mathrm{NaOH}$ aqueous solution, at a constant temperature of $160^{\circ} \mathrm{C}$, in a helium atmosphere, and during a period of time from 0.5 to $1.5 \mathrm{~h}$.

Table 4 shows that appropriate time to obtain the best yield is 1 hour. Below one hour the yield decreases and above it, oxidation and esterification reactions are favored,
Table 4. Effect of the reaction time.

\begin{tabular}{cccc}
\hline Reaction time [h] & 0.5 & 1.0 & 1.5 \\
\hline Yield [\%] & 61.2 & 71.7 & 42.9 \\
\hline
\end{tabular}

thus, by-products such as benzylbenzoate and benzylcinnamate may appear (Figure 5). This can be observed in Figure 6, at the $13.3 \mathrm{~min}$ and $14.94 \mathrm{~min}$ peaks, respectively.

\subsection{Effect of the Solvent}

The different solvents used as the reaction media are shown in Table 5. When alcohols are used as solvent, the production of coumaric acid is very low, because the 


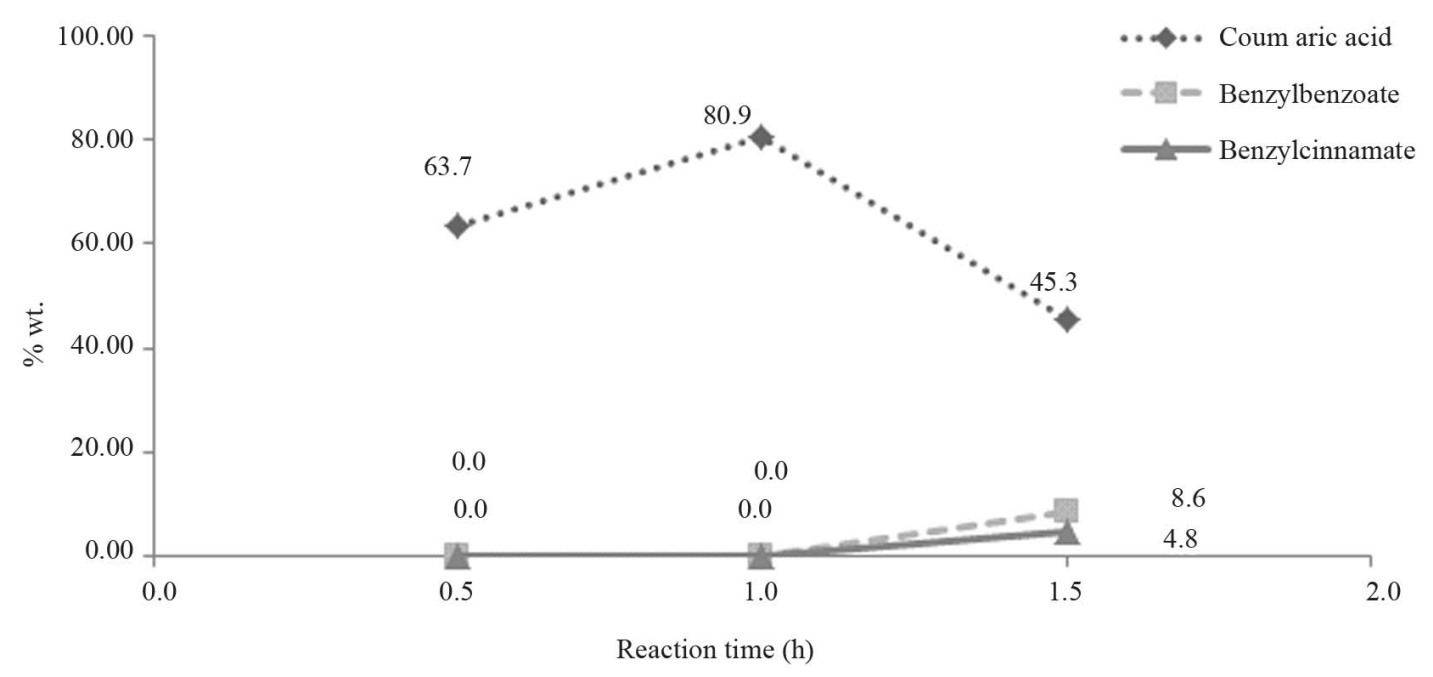

Figure 5. Effect of the reaction time.

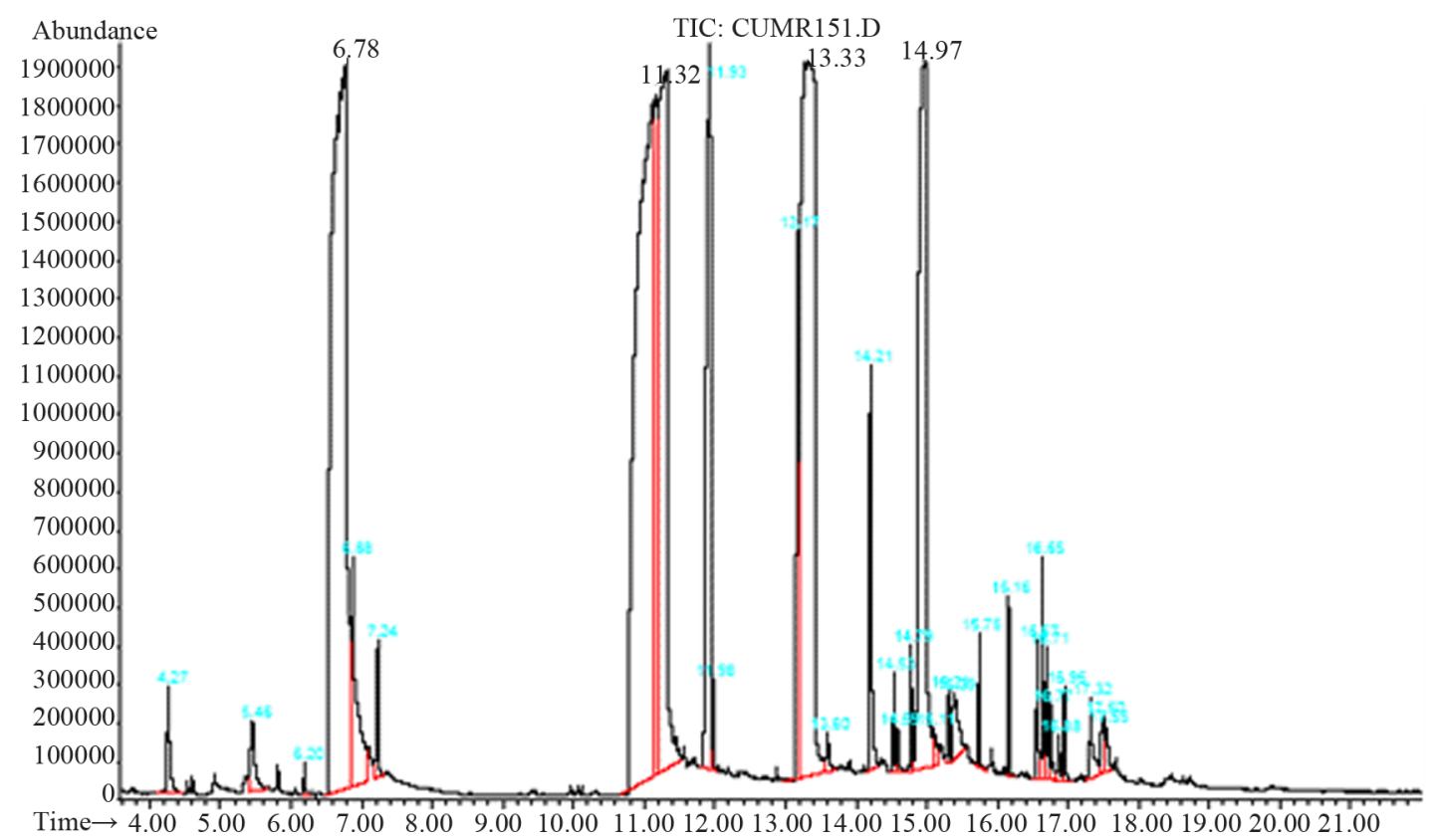

Figure 6. Chromatogram of by-products obtained when the reaction was carried out at a reaction time greater than 1 hour.

Table 5. Effect of the solvents.

\begin{tabular}{cccc}
\hline Solvent & Water & Methanol & Ethanol \\
\hline Yield [\%] & 71.7 & 14.2 & 0.1 \\
\hline
\end{tabular}

group -OH may cause interference with the reaction (Figure 7). Hence, the best solvent fot this reaction is water.

\subsection{Characterization and Identification}

At the optimal reactions conditions, coumaric acid can be obtained by opening the lactone ring and cis-trans isomerization. The resulting chromatograms are shown in
Figure 8, where the presence of coumaric acid (8.42 min) and coumarin (12.11 min) can be observed.

Once the extraction is finished, the coumaric acid obtained had a 97\% purity. Figure 9 also shows the coumaric acid standard from Aldrich (b). The melting point of coumaric acid is $208^{\circ} \mathrm{C}$ with decomposition.

\section{Conclusions}

Methods found in literature for the production of coumaric acid may lead to the formation of raw materials or undesired products; however, it has been proven that coumaric acid can be obtained from coumarin with the conditions established in this paper. 


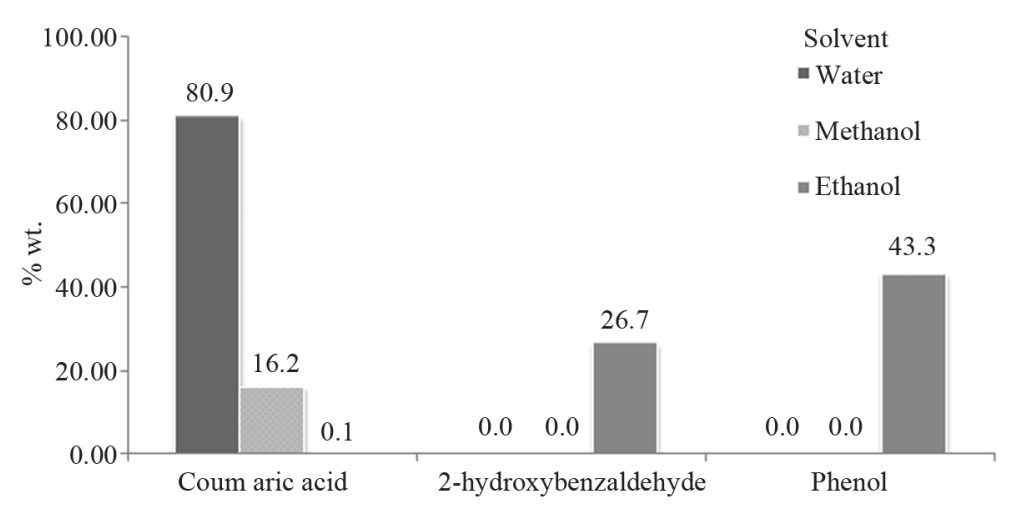

Figure 7. Effect of the solvents.

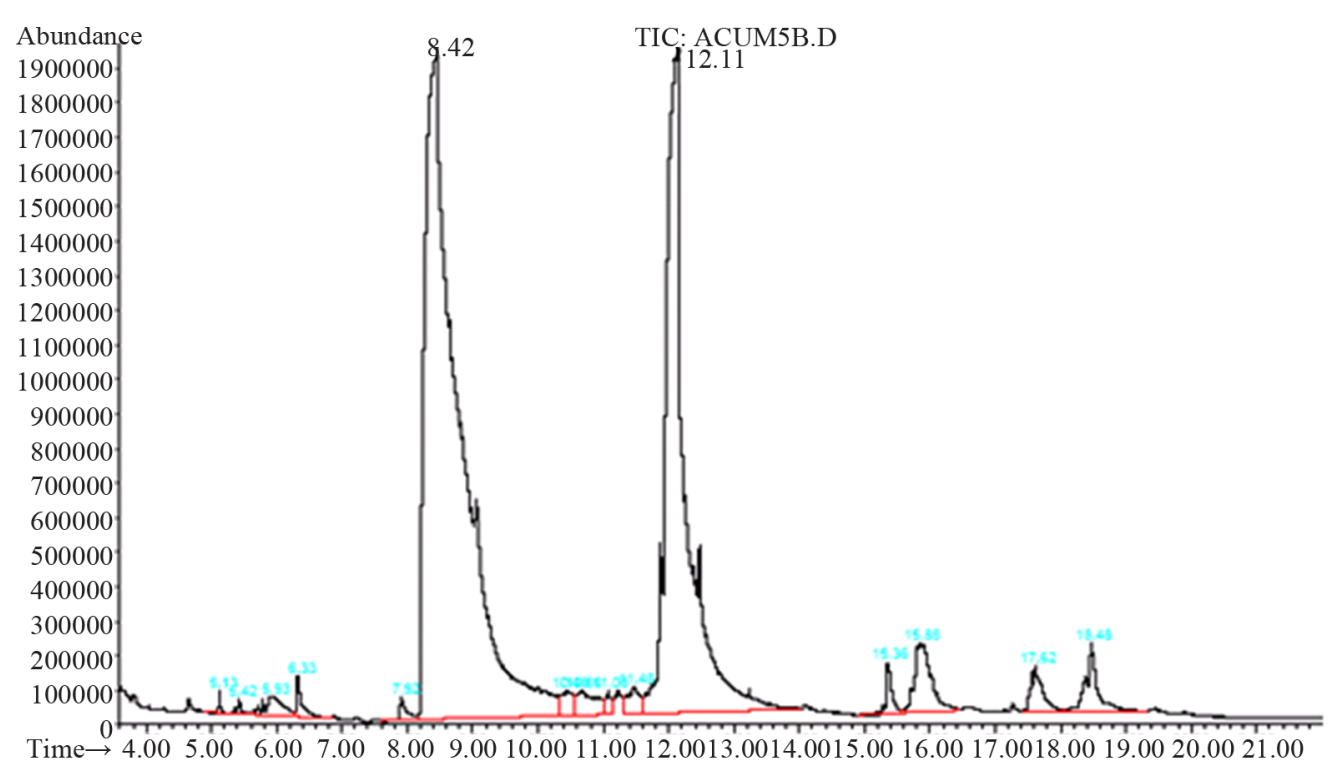

Figure 8. Chromatogram of reaction products.

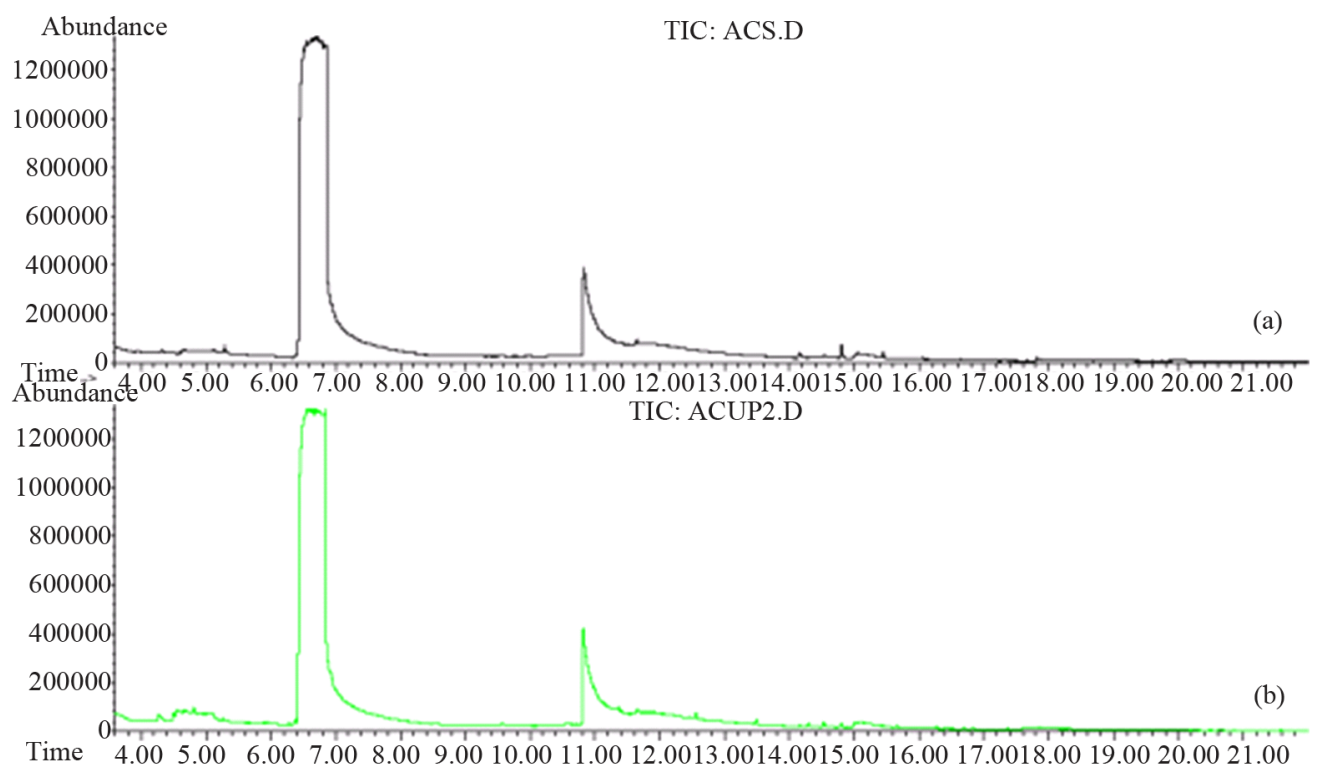

Figure 9. Chromatogram of coumaric acid obtained with the optimal reaction conditions (a) compared to the coumaric acid standard from Aldrich (b). 
Under the selected experimental conditions, i.e., temperature of $160^{\circ} \mathrm{C}$, reaction time of $1 \mathrm{~h}$, with $20 \%$ sodium hydroxide aqueous solution, and carrying out the reaction in an inert atmosphere; coumaric acid is produced from coumarin when the lactone ring is opened through basic hydrolysis, as long as the double bond changes from cis to trans.

By applying the above mentioned parameters, the reaction yield is $70 \%$, which represents an improvement over other methods proposed in literature. Furthermore, these conditions allow the ring opening and prevent the formation of by-products such as phenol, 2-hydroxybenzaldehyde, benzylbenzoate and benzylcinnamate.

\section{Acknowledgements}

The authors wish to acknowledge the help of Unidad de Servicio de Apoyo a la Investigación (USAI), Facultad de Química, UNAM, México, for their technical support.

\section{REFERENCES}

[1] R. E. Kirk and D. F. Othmer, "Encyclopedia of Chemical Technology,” 5th Edition; John Wiley \& Sons Ltd., Chichester, 2007.

[2] J. R. S. Hoult and M. Paydt, "Pharmacological and Biochemical Actions of Simple Coumarins: Natural Products with Therapeutic Potential,” General Pharmacology, Vol. 27, No. 4, 1996, pp. 713-722. doi:10.1016/0306-3623(95)02112-4

[3] E. M. Agostinha, R. Matos, C. C. S. Sousa, et al., "Energetics of Coumarin and Chromone" The Journal of Physical Chemistry B, Vol. 113, No. 32, 2009, pp. 1121611221. doi:10.1021/jp9026942

[4] J. Preat, D. Jacquemin, et al., "Theoretical Investigation of Substituted Anthraquinone Dyes,” Journal of Chemical Physics, Vol. 415, No. 20, 2005, pp. 1736-1743. doi:10.1063/1.1764497

[5] B. A. Chauder, C. C. Lopes, R. S. C. Lopes, A. J. M. da Silva and V. Snieckus, "Phenylboronic Acid-Mediated Synthesis of 2H-Chromenes," Synthesis, Vol. 1998, No. 3, 1998, pp. 279-282. doi:10.1055/s-1998-2042

[6] K. A. Parker and T. L. Mindt, "Electrocyclic Ring Closure of the Enols of Vinyl Quinones. A 2H-Chromene Synthesis," Organic Letters, Vol. 3 No. 24, 2001, pp. 3875-3878. doi:10.1021/ol0167199

[7] I. H. Updergraff and H. G. Cassidy, "Electron Exchange-Polymer II. Vinylhydroquinone Monomer and Polymer," Journal of the American Chemical Society, Vol. 71, No. 407, 1949, pp. 407-410. doi:10.1021/ja01170a010

[8] S. Patai, "The Chemistry of Functional Groups. The Chemistry of Quinoid Compounds. Part 2,” 1st Edition, John Wiley \& Sons Ltd., Chichester, 1974.

[9] D. Burton and D. Ollis "Comprehensive Organic Chemistry. (The Synthesis and Reactions of Organic Compounds),” 1st Edition, Pergamon Press, Oxford, 1979.

[10] R Murray, J Mendez and S. Brown, "The Natural Coumarins,” John Wiley \& Sons, Chichester, 1997.

[11] E. Cingolani, "Idrolisi del Ciclo Cumarinico e Transformazione cis-Trans Degli Acidi O-Ossicinnamici," Gazzeta, Vol. 89, No. 5, 1959, pp. 195-1998.

[12] E. Cingolani, “Trasformazione Degli Acidi Cumárico (Trans O-Ossicinnamici) Nelle Cumarina Corrispondenti,” Gazzetta, Vol. 46, No. 9, 1959, pp. 999-1008.

[13] D. Bihari and K. Krishna, "Action of Sodium Sulphite on Coumarins," Journal of the American Chemical Society, Vol. 46, No. 3, 1924, pp. 554-564.

[14] R. Adams and T. E. Bockstahler, "Preparation and Reactions of O-Hydroxycinnamic Acids and Esters,” Journal of the American Chemical Society, Vol. 74, No. 21, 1952, pp. 5346-5348. doi:10.1021/ja01141a038

[15] F. D. Dodge, "Some Derivatives of Coumarin,” Journal of the American Chemical Society, Vol. 38, No. 2, 1916, pp. 446-457. doi:10.1021/ja02259a030 